\title{
Redo Mitral Valve Replacement through Right Thoracotomy on Beating Heart
}

\author{
Mohammad Salman Siddiqi ${ }^{1}$, Ashok Kumar Sharma ${ }^{2 *}$ and Hilal Al sabti ${ }^{1}$ \\ ${ }^{1}$ Department of Cardiothoracic Surgery, Senior Specialist, Cardiothoracic Surgery, Oman \\ ${ }^{2}$ Department of Cardiothoracic Surgery, Senior Senior Consultant, Sultan Qaboos University Hospital, Oman and Formerly Director, Wakefield Heart \\ Centre, Newzealand
}

Submission: December 04, 2016; Published: December 20, 2016

*Corresponding author: Ashok Kumar Sharma, Senior Consultant, Cardiothoracic Surgery Division, P0 Box 35, Sultan Qaboos University Hospital, Post Code - 123, Muscat, Oman, Tel: +968-99588727; Fax: +968-24143504; Email : drashoksharma1@gmail.com

\begin{abstract}
Redo mitral surgery via sternotomy can be associated with significant complications, including injuries to the heart, great vessels and patent coronary artery grafts, especially internal mammary artery leading to excessive blood loss, and may increase morbidity and mortality in these patients [1]. The right antero-lateral thoracotomy offers excellent exposure with less risk from re-entry associated complications. This approach is particularly valuable in patients with patent coronary bypass grafts avoiding the risk of perioperative graft injury. Resternotomy after coronary artery bypass grafting (CABG) is a technically challenging situation, especially in the presence of patent grafts. In this case report we present a case with a previous coronary bypass grafting along with mitral valve repair 15 years back, and stenting to left anterior descending artery (LAD) 2 years ago. Patient underwent on-pump beating heart normothermic mitral valve replacement without cross-clamping the aorta through right anterolateral thoracotomy.
\end{abstract}

Keywords: Redo Mitral Valve; Beating Heart; Right Thoracotomy

Case Report

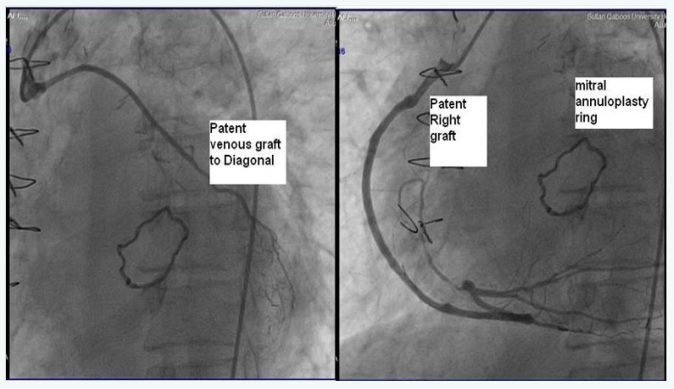

Figure 1: Preoperative coronary angiogram.

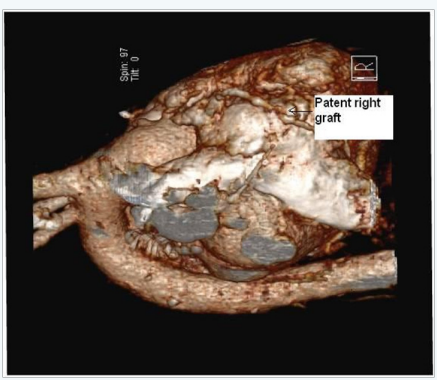

Figure 2: Preoperative CT angiogram.
A 58 year old female presented with increasing shortness of breath. Patient had history of coronary bypass surgery and mitral valve repair 5 year back. The patient had New York Heart Association class 4 symptoms. Transthoracic echocardiography showed severe mitral regurgitation. Coronary angiography and CT cardiac showed patent saphenous vein graft to diagonal and posterior descending artery and atretic and thinned out LIMA graft, patent LAD stent (Figures 1 \& 2). Patient had right anterolateral thoracotomy through $4^{\text {th }}$ intercostal space. Left atrium was opened through sulcus of sondergord. The ascending aorta and right atrium was used for cannulation. The ascending aorta and right superior pulmonary vein was vented for deairing and to maintain a bloodless surgical field. The surgery was performed under normothermic cardiopulmonary bypass without aortic cross clamping. The mitral valve was thickened fibrotic appeared to be rheumatic, and was not suitable for repair. Annuloplasty ring and anterior leaflet of the mitral were valving excised (Figures 3-5). The mitral valve replacement was done with 25 hancock 2 bioprosthetic valve using interrupted pledgeted sutures (Figure 6). The CPB time was 68 minutes. Postoperative bleeding was $250 \mathrm{ml}$ and patient was extubated 
after three hours. Post-operative period was uneventful and the patient was discharged on the sixth postoperative day.
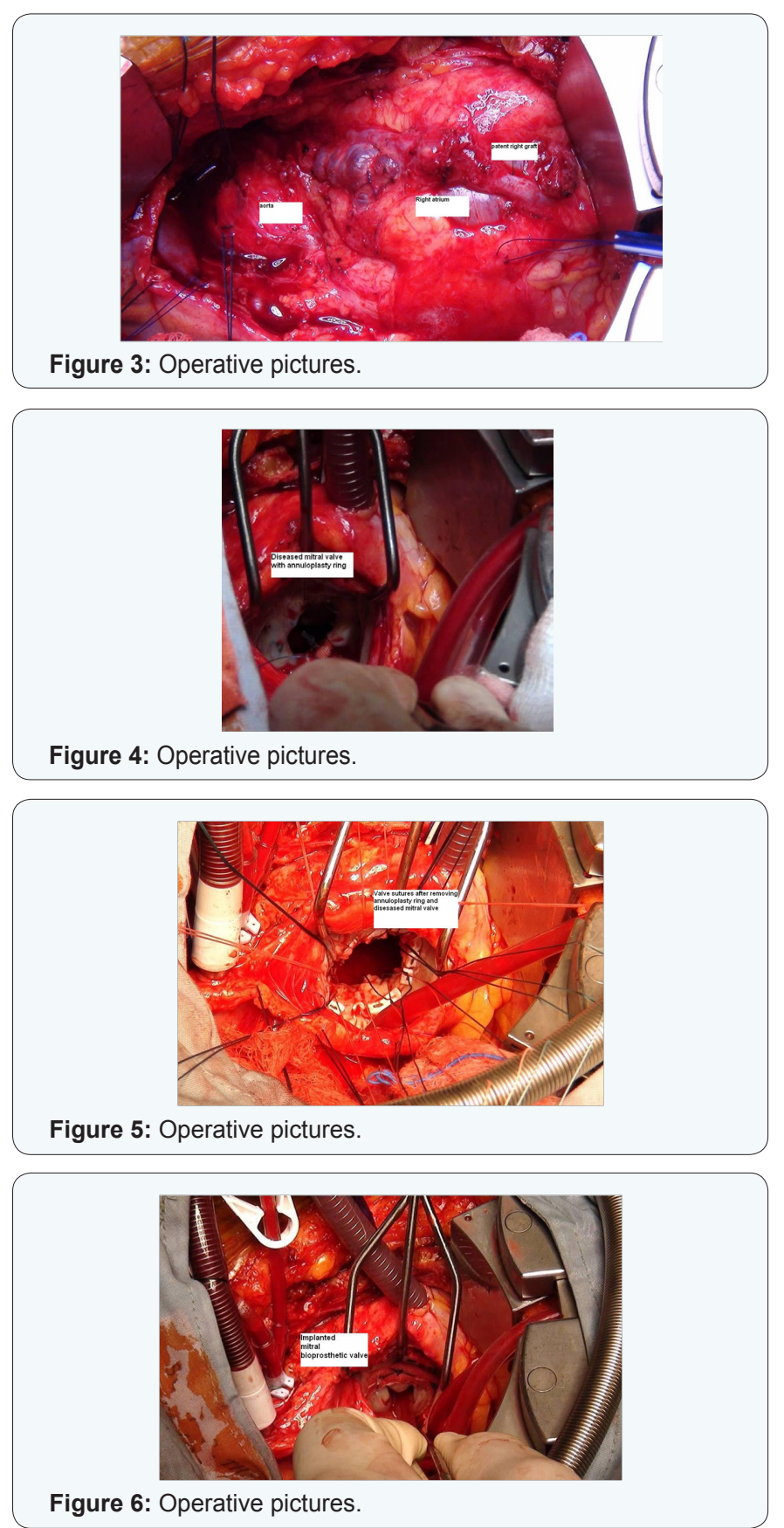

\section{Discussion}

As life expectancy is increasing reoperative cardiac surgery continues to increase, techniques that are safe and easily reproducible should be adopted. Redo cardiac surgery is technically challenging due to increased rate of perioperative morbidity and mortality [2,3]. Redo mitral valve surgery is increasing because of increase of mitral valve repair and increasing use of bioprosthetic valve replacement over past few decades and these patients are coming for reoperation over the period of time. Resternotomy has its own inherent risk of injury to previous patent grafts, which can be catastrophic, injury to cardiac structures and great vessels [4]. It minimizes dissection of adhesions, avoids injury to right ventricle and prevents damage to patent grafts, which translates into reduced blood loss, less blood transfusions and expedited recovery [5]. Besides the above mentioned advantage beating heart repair/ replacement prevents myocardial damage caused by ischemiareperfusion injury by normothermic continuous myocardial perfusion.

Normothermic perfusion also reduces the coagulopathy [1]. Through this approach pericardial dissection is limited to left atrial incision, which is quite safe and also saves time. It also provides good exposure to mitral valve with only moderate retraction. But this approach can have some disadvantages also. The major challenge while the heart is kept beating is to provide a relatively bloodless operative field, which can be achieved by putting sump suckers in left atrium and left ventricular venting. Another area of concern is the risk of air embolism. Trendlenberg position, continuous aortic venting, use of carbon dioxide gas insufflations of the operative field, vacuum assisted drainage are useful methods for preventing air embolism $[1,6]$. Ricci and colleagues in their series reported no incidence of neurological deficit due to air embolism [7]. According to Romano et al, right anterolateral thoracotomy mitral valve surgery in a redo case without cross clamping on the beating heart is associated with shorter bypass time, less post operative transfusion requirements, shorter postoperative ventilation, and lower mortality than with conventional surgery [8].

\section{Conclusion}

Redo on-pump beating normothermic mitral valve replacement without cross-clamping the aorta through right anterolateral thoracotomy is a simple and safe procedure, especially in patients with patent bypass grafts.

\section{References}

1. Thompson MJ, Behranwala A, Campanella C, Walker WS, Cameron EW (2003) Immediate and long term results of mitral prosthetic replacement using a right thoracotomy beating heart technique. Eur J Cardiothorac Surg 24(1): 47-51.

2. Morales D, Williams E, John R (2010) Is sternotomy in cardiac surgery still a problem? Interact Cardiovasc Thorac Surg 11(3): 277-286.

3. Botta L, Cannata A, Fratto P, Bruschi G, Trunfio S, et al. (2012) The role of minimally invasive beating heart technique in reoperative valve surgery. J Card Surg 27(1): 24-28.

4. Stiemle CN, Bolling SF (1996) Outcome of reoperative valve surgery via right thoracotomy. Circulation 94(9 Suppl): II 126-128.

5. Holman WL, Goldberg SP, Early LJ, Mcgiffin DC, Kirklin JK, et al. (2000) Right thoracotomy for mitral reoperation: analysis of technique and outcome. Ann Thorac Surg 70(6): 1970-1973.

6. Ciçekcioğlu F, Tütün U, Parlar AI, Aksöyek A, Babaroğlu S, et al. (2007) Mitral valve replacement on a beating heart through right thoracotomy in a patient with patent coronary grafts. Anadolu Kardiyol Derg 7(2): 247-248. 
7. Ricci M, Macedo FI, Suarez MR, Brown M, Alba J, et al. (2009) Multiple valve surgery with beating heart technique. Ann Thorac Surg 87(2) 527-531.
8. Romano MA, Haft JW, Pagani FD, Bolling SF (2012) Beating heart surgery via right thoracotomy for reoperative mitral valve surgery: a safe and effective operative alternative. J Thorac Cardiovasc Surg 144(2): 334-339. 